\title{
Morphogen Electrochemically Triggered Self-Construction of Polymeric Films Based on Mussel-Inspired Chemistry
}

\author{
Clément Maerten, ${ }^{\dagger}$ Tony Garnier, ${ }^{\dagger}$ Paolo Lupattelli, ${ }^{\dagger, \ddagger}$ Nguyet Trang Thanh Chau, ${ }^{\dagger}$ \\ Pierre Schaaf, ${ }^{\dagger, \S, \|, \perp, \#, \otimes, \$}$ Loïc Jierry, ${ }^{*},, \S, \|$ and Fouzia Boulmedais ${ }^{*}, \dagger, \uparrow$ \\ ${ }^{\dagger}$ Institut Charles Sadron, Centre National de la Recherche Scientifique, Université de Strasbourg, 23 Rue du Loess, 67034 Strasbourg \\ Cedex 2, France \\ ${ }^{\ddagger}$ Dipartimento di Scienze, Università degli Studi della Basilicata, Via dell’Ateneo Lucano 10, 85100 Potenza, Italy \\ ${ }^{\S}$ Université de Strasbourg, Ecole de Chimie, Polymères et Matériaux, 25 Rue Becquerel, 67087 Strasbourg, France \\ "University of Strasbourg, Institute of Advanced Study, 5 Allée du Général Rouvillois, 67083 Strasbourg, France \\ ${ }^{\perp}$ Institut National de la Santé et de la Recherche Médicale, UMR-S 1121, Biomatériaux et Bioingénierie, 11 Rue Humann, 67085 \\ Strasbourg Cedex, France

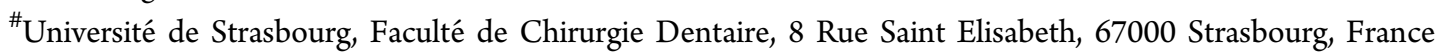 \\ ${ }^{\otimes}$ International Center for Frontier Research in Chemistry, 8 Allee Gaspard Monge, 67083 Strasbourg, France \\ ${ }^{\$}$ Institut Universitaire de France, 3 Boulevard Saint-Michel, 75005 Paris, France
}

Supporting Information

ABSTRACT: Inspired by the strong chemical adhesion mechanism of mussels, we designed a catechol-based electrochemically triggered self-assembly of films based on ethylene glycol molecules bearing catechol groups on both sides and denoted as bis-catechol molecules. These molecules play the role of morphogens and, in contrast to previously investigated systems, they are also one of the constituents, after reaction, of the film. Unable to interact together, commercially available poly(allylamine hydrochloride) (PAH) chains and biscatechol molecules are mixed in an aqueous solution and brought in contact with an electrode. By application of defined potential cycles, bis-catechol molecules undergo oxidation leading to molecules

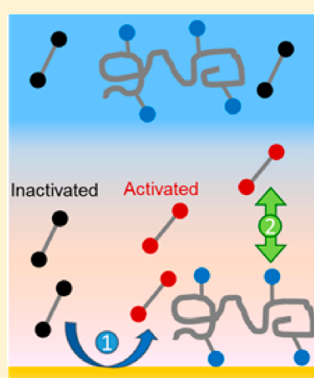

Gold electrode

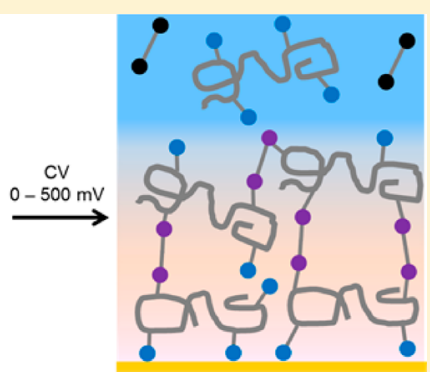

Gold electrode bearing "reactive" quinone groups which diffuse toward the solution. In this active state, the quinones react with amino groups of PAH through Michael addition and Schiffs base condensation reaction. The application of cyclic voltammetry $(\mathrm{CV})$ between 0 and $500 \mathrm{mV}$ (vs Ag/AgCl, scan rate of $50 \mathrm{mV} / \mathrm{s}$ ) of a PAH/biscatechol solution results in a fast self-construction of a film that reaches a thickness of $40 \mathrm{~nm}$ after 60 min. The films present a spiky structure which is attributed to the use of bis-functionalized molecules as one component of the films. XPS measurements show the presence of both PAH and bis-catechol cross-linked together in a covalent way. We show that the amine/catechol ratio is an important parameter which governs the film buildup. For a given amine/catechol ratio, it does exist an optimum CV scan rate leading to a maximum of the film thickness as a function of the scan rate.

\section{INTRODUCTION}

During the last decades, nature has gradually become an important source of inspiration in science. The study of natural phenomena not only allows understanding the world around us but also permits designing new materials with specific properties. Mussels are common mollusks that can stick to all kinds of materials such as rocks, wood, metals, and glass even under extreme conditions (low temperature, salted water). Catechol bearing proteins appear to be directly involved in the adhesion mechanism. ${ }^{1,2}$ Inspired by this extremely strong natural adhesive, researchers attempt to mimic this bioglue., Catechols present a broad panel of possibilities for chemistry. ${ }^{5}$ In particular, they can be oxidized into quinones which undergo Michael addition and Schiff's base formation with nucleophilic groups such as amines or thiols. Several synthetic approaches were developed for the design of novel catechol-based polymer materials and for functionalization of surfaces. ${ }^{6}$

Surface functionalization allows controlling the interaction of materials with their surrounding environment. Catalysis, molecular recognition, or cell adhesion are typical examples of such interactions. During the last decades, progress in surface science allowed modifying and tuning material's surface properties in a highly controlled way by the development of new coating methods. Among them, the use of an external

Received: October 9, 2015

Revised: November 16, 2015

Published: November 17, 2015 
a<smiles>O=C(COCCOCCOCC(=O)NCCc1ccc(O)c(O)c1)NCCc1ccc(O)c(O)c1</smiles>

b
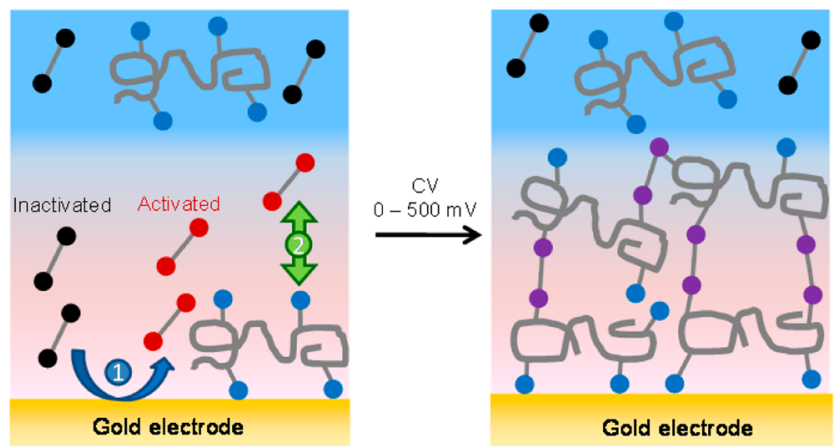

Poly(allylamine)<smiles>CCCC(C)(C)CN</smiles>

Figure 1. (a) Chemical structures of bis-catechol and poly(allylamine hydrochloride) (PAH). (b) Principle of the one pot self-construction of polymeric film based on oxidation of an organic morphogen (bis-catechol).

stimulus, such as an electric signal or light, appears as a convenient way of inducing a film buildup in a one pot manner. Electrochemically triggered formation of polymeric films can be divided into three categories: (i) precipitation of polyelectrolytes, $^{7-9}$ (ii) self-assemblies of polyelectrolytes, ${ }^{10,11}$ polysaccharides $^{12,13}$ or proteins, ${ }^{14-17}$ and (iii) electropolymerization. ${ }^{18}$ Recently, we introduced a fourth category of polymericfilm electro-construction based on the formation of covalent bonds between polymers ${ }^{19-23}$ induced by an electro-generated gradient of "active" molecules called "morphogens". First introduced by Turing, ${ }^{24}$ morphogens are specific molecules to which cells respond in a concentration-dependent manner. ${ }^{25}$ This definition has been extended to film-buildups on a surface where morphogens are molecules or ions that induce a chemical reaction or interaction in a confined space near a surface. In a first study, we used the Huisgens-Sharpless click reaction to induce the reticulation between two polymers by electroreduction of $\mathrm{Cu}^{2+}$ into $\mathrm{Cu}^{+}{ }^{19}$ Generated at the surface of the electrode, $\mathrm{Cu}^{+}$ions (the morphogens) diffuse from the surface to the solution and catalyze the click reaction between azide and alkyne functionalized polymers. As this reaction takes place only in the presence of $\mathrm{Cu}(\mathrm{I})$, all the constituents can be mixed in a single solution and the film formation takes place by the simple application of an electrical stimulus. In 2012, Payne and co-workers electrogenerated chlorine species $(\mathrm{HOCl})$ to partially oxidize chitosan forming aldehydes that can react covalently with amines (from chitosan itself or proteins) present simultaneously in solution. ${ }^{26}$

Inspired by the chemical versatility of the catechol group to cross-link suitable polymers, we report here a new example of morphogen driven film construction based on short ethylene glycol chains bearing catechol groups on both sides. These molecules will be denoted as bis-catechols (Figure 1a). Unable to cross-link together, a commercially available poly(allylamine hydrochloride) (PAH) and these bis-catechol molecules will be mixed in an aqueous solution and put into contact with an electrode. By application of a defined electrochemical potential, the bis-catechol molecules will undergo an oxidation at the electrode, transforming into an "active" state (bis-quinone) (Figure $1 \mathrm{~b}$ ). In this active state, the bis-quinone molecules can react with the amino groups of $\mathrm{PAH}$ through Michael addition and Schiff's base condensation (Scheme 2). The film buildup, occurring exclusively near the electrode, is by far not obvious because (i) the diffusion of bis-catechol molecules toward the electrode has to be ensured all along the buildup process, even after the beginning of the film formation, and (ii) the two ends of the bifunctionalized molecules could react with the same polymer chain and thereby become unavailable to continue the self-construction process. In contrast to previously reported morphogen driven film constructions, this constitutes the first example of such a film-buildup where the morphogen is also an essential component of the film. This represents an extension of the morphogen definition introduced in 2011 . $^{19}$

\section{MATERIALS AND METHODS}

Chemicals. Poly(allylamine hydrochloride) (PAH, $M_{w}=58000 \mathrm{~g} /$ mol, CAS 71550-12-4), poly(diallyldimethylammonium chloride) (PDADMA, $M_{\mathrm{w}} \approx 97000 \mathrm{~g} / \mathrm{mol}$, CAS 26062-79-3). In both polymers, the $M_{\mathrm{w}}$ were supplied by the provider. Sodium nitrate $\left(\mathrm{NaNO}_{3}, \quad M=84.99 \mathrm{~g} / \mathrm{mol}\right.$, CAS 7631-99-4), potassium hexacyanoferrate(II) ( $M=422.41 \mathrm{~g} / \mathrm{mol}$, CAS 14459-95-1), 4-(2hydroxyethyl)piperazine-1-ethanesulfonic acid (HEPES) were purchased from Sigma-Aldrich. $\mathrm{D}_{2} \mathrm{O}$ (99\%) was purchased from Eurisotop. All chemicals were used as received. All the polymer solutions were prepared using $10 \mathrm{mM}$ HEPES/ $150 \mathrm{mM} \mathrm{NaNO}_{3}$ aqueous buffer adjusted to $\mathrm{pH} 7.4$ with $\mathrm{NaOH}$ and $\mathrm{HNO}_{3}$ solutions. $\mathrm{PAH} /$ biscatechol mixture solutions were prepared at $1 \mathrm{mg} / \mathrm{mL}$ in $\mathrm{PAH}$ and 1 $\mathrm{mg} / \mathrm{mL}$ in bis-catechol corresponding to a catechol/amine ratio of 0.38 , unless otherwise stated. Argon was flushed through all the PAH/ bis-catechol solutions to prevent oxidation in solution due to dissolved oxygen. Keeping the mass concentration of PAH constant, the catechol/amine ratio was varied from 0.02 to 0.95 by changing the mass concentration from 0.06 to $2.5 \mathrm{mg} / \mathrm{mL}$ in bis-catechol.

Electrochemical Quartz Crystal Microbalance (EC-QCM) with Dissipation Monitoring. The electrochemical quartz microbalance (EC-QCM) experiments were performed on a Q-Sense E1 apparatus from Q-Sense AB (Gothenburg, Sweden) by monitoring the changes in the resonance frequency $f_{\nu}$ and the dissipation factor $D_{\nu}$ of an oscillating quartz crystal upon adsorption of a viscoelastic layer $(\nu$ represents the overtone number, equal to $1,3,5,7)$. The quartz crystal was excited at its fundamental frequency $(5 \mathrm{MHz})$, and the measurements were performed at the first, third, fifth, and seventh overtones, corresponding to $5,15,25$, and $35 \mathrm{MHz}$, respectively. The QCM measurement is sensitive to the amount of water associated with the adsorbed molecules and senses the viscoelastic changes in the interfacial material. Only the third overtone at $15 \mathrm{MHz}$ is presented. The gold-coated QCM sensor acted as working electrode. A platinum electrode (counter electrode) on the top wall of the chamber and a no- 
Scheme 1. Synthetic Pathway to Prepare Bis-Catechol in Five Steps from Commercially Available Dopamine and TUDA

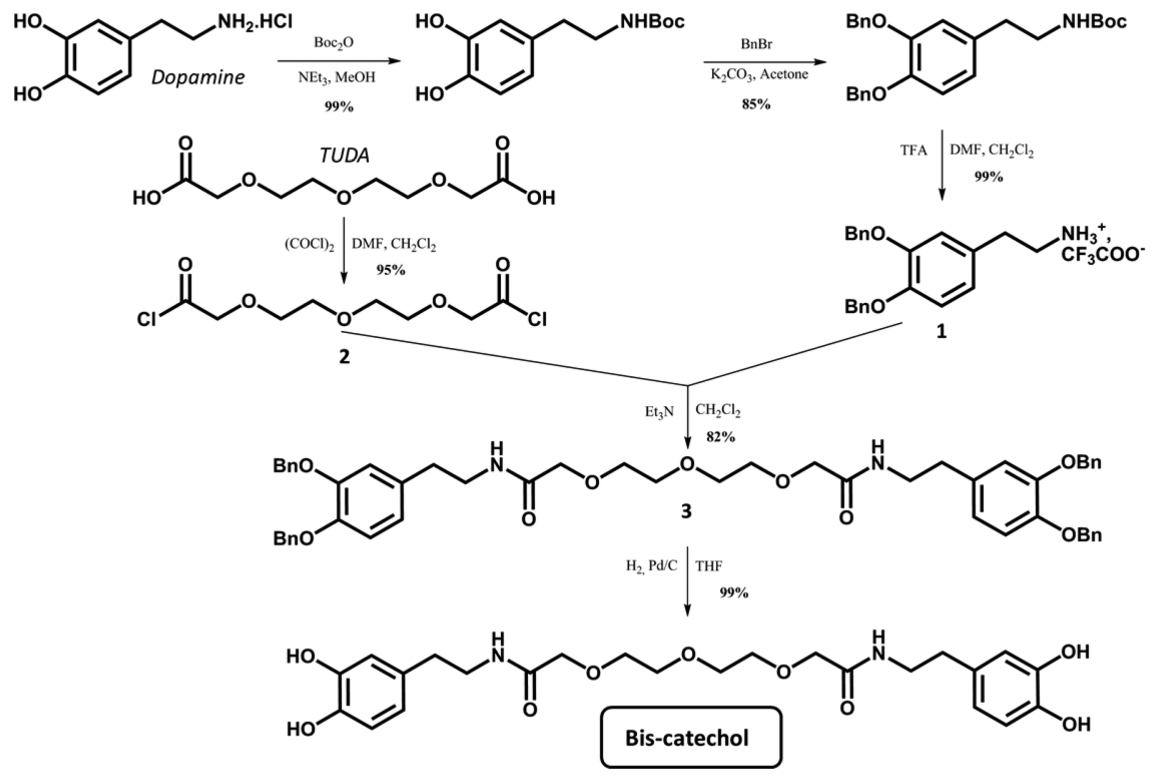

leak $\mathrm{Ag} / \mathrm{AgCl}$ reference electrode fixed in the outlet flow channel were used, respectively, as counter and reference electrodes. Electrochemical measurements were performed on a $\mathrm{CHI} 660 \mathrm{E}$ apparatus from $\mathrm{CH}$ instrument (Austin, Texas) coupled on the QCM-D (named ECQCM) apparatus. Before the buildup of the polymer film, in order to test the quality of the EC-QCM cell, a capacitive current and a faradic current of a $1 \mathrm{mM}$ of potassium hexacyanoferrate(II) aqueous solution were recorded. A $150 \mathrm{mM} \mathrm{NaNO}=10 \mathrm{mM}$ HEPES buffer was prepared to measure the capacitive current of the EC-QCM cell. The 1 $\mathrm{mM}$ of potassium hexacyanoferrate(II) was prepared in $10 \mathrm{mM}$ HEPES-150 $\mathrm{mM} \mathrm{NaNO}_{3}$ buffer solution and put in contact with the crystal to monitor its cyclic voltammogram taken as reference. We verified the presence of the two peaks and the potential values of the oxidation and reduction of the potassium hexacyanoferrate(II).

Film Buildup Procedure and Conditions of CV Experiments. After stabilization of the QCM signal in contact with $10 \mathrm{mM}$ HEPES$150 \mathrm{mM} \mathrm{NaNO}{ }_{3}$ buffer solution, a mixture of PAH and bis-catechol (in $10 \mathrm{mM}$ HEPES $-150 \mathrm{mM} \mathrm{NaNO}_{3}$ buffer solution at $\mathrm{pH}=7.4$ ) was injected in the electrochemical cell $(600 \mu \mathrm{L})$ at a flow rate of $600 \mu \mathrm{L} /$ min with a peristaltic pump. After stabilization of the signal, cyclic voltammetry between 0 and $500 \mathrm{mV}$ (vs $\mathrm{Ag} / \mathrm{AgCl}$, scan rate $50 \mathrm{mV} / \mathrm{s}$ unless otherwise stated) was applied to trigger the catechol oxidation into quinone and start the self-construction of the film. After the selfconstruction, cylic voltammetry was stopped and a rinsing step was performed by injection of an aqueous solution of $10 \mathrm{mM}$ HEPES-150 $\mathrm{mM} \mathrm{NaNO} 3(600 \mu \mathrm{L})$. The gold working electrode was then unmounted from the EC-QCM cell, rinsed, and stored into ultrapure water for further characterizations in AFM.

Atomic Force Microscopy. Self-constructed films, built on QCM crystals, were characterized by AFM. AFM images were obtained in contact mode in liquid conditions with the Nanoscope IV from Veeco (Santa Barbara, CA). Because of the fact that our films are mechanically robust, we selected the contact mode because it allows rapid imaging even on wet conditions. Cantilevers with a spring constant of $0.03 \mathrm{~N} / \mathrm{m}$ and silicon nitride tips (model MSCTAUHW, Veeco) were used. We always performed several scans over a given surface area. These scans had to produce comparable images to ascertain that there is no sample damage induced by the tip. Deflection and height images were scanned at a fixed scan rate $(1 \mathrm{~Hz})$ with a resolution of $512 \times 512$ pixels. The film thickness was measured by using the "scratch" method. The scratches were made with a plastic cone tip and were always imaged perpendicular to the fast scan axis. Profilometric section analysis of a scratched film allowed us to determine precisely the thickness of the film over the scanned area. We define the film thickness as the minimal $z$ distance between the bare substrate and the surface of the film which covers the whole substrate. The mean thickness of the scratched film was determined by measuring the thickness on at least three areas. The film roughness is the RMS given by the AFM software on $10 \mu \mathrm{m} \times 10 \mu \mathrm{m}$ images. Data evaluations were performed with the NanoScope software version 5.31r1 (Digital Instruments, Veeco).

X-ray Photoelectron Spectroscopy. The chemical composition of the films was determined by X-ray photoelectron spectroscopy (XPS) analysis. This analysis was performed with a Thermo VG Scientific spectrometer, equipped with an $\mathrm{Al} \mathrm{K} \alpha$ X-ray source (1486.6 $\mathrm{eV}$ ). It operated at $225 \mathrm{~W}$ under ultrahigh vacuum (pressure lower than $5.0 \times 10^{-8} \mathrm{mbar}$ ). The incidence angle and the source-to-analyzer angle were set to $45^{\circ}$ and $90^{\circ}$, respectively. The probing depth of the technique was estimated to range from 5 to $8 \mathrm{~nm}$. The survey scans were collected from 0 to $1100 \mathrm{eV}$ with pass energy of $50 \mathrm{eV}$ and the high-resolution scans were performed with the pass energy adjusted to $20 \mathrm{eV}$. The spectra were recorded by the Avantage V.2.26 software and analyzed by the Casa XPS 2.3.16 software. The Au 4f7/2 and Au 4f5/2 peaks were set to 84.0 and $87.0 \mathrm{eV}$, respectively, as the calibration of the energy scale. Raw areas determined after background subtraction were corrected according to Scofield sensitivity factors (C 1s, 1.00; N 1s, 1.80; and $\mathrm{O} 1 \mathrm{~s}, 2.93)$. The curve fitting was performed using a convolution of Gaussian and Lorentzian line shapes with a typical ratio of 70:30. This peak-fitting procedure was repeated until an acceptable fit was obtained with consideration of peak position and full width at half-maximum. The analysis was performed on a film self-constructed during $60 \mathrm{~min}$ from PAH $(1 \mathrm{mg} / \mathrm{mL})$ and bis-catechol $(2.03 \mathrm{mM})$ according to parameters previously described.

Bis-Catechol Synthesis. Bis-catechol is an original molecule displaying a catechol group at each end of a linear oligoethylene oxide chain. This hydrophilic molecule is stable and water-soluble. Biscatechol was prepared in five steps from dopamine and 3,6,9trioaundecandioic acid (TUDA), both commercially available starting materials (Scheme 1). Briefly, first dopamine is modified in three steps according to the literature ${ }^{27}$ to get the trifluoroacetate salt of $2-(3,4-$ bis-benzylyoxyphenyl)-ethylamine 1 in $84 \%$ overall yield. Then, in the presence of a half equivalent of trioxaundecanedioyl chloride 2 (prepared in one step from TUDA) in basic conditions, the benzylprotected bis-catechol 3 is obtained in $82 \%$. Finally, a last hydrogenolysis step provides bis-catechol in a quantitative way. The overall yield of this synthesis is $68 \%$ and it has been realized on a multigram scale. The experimental description of the total synthesis of bis-catechol is given in the Supporting Information. 

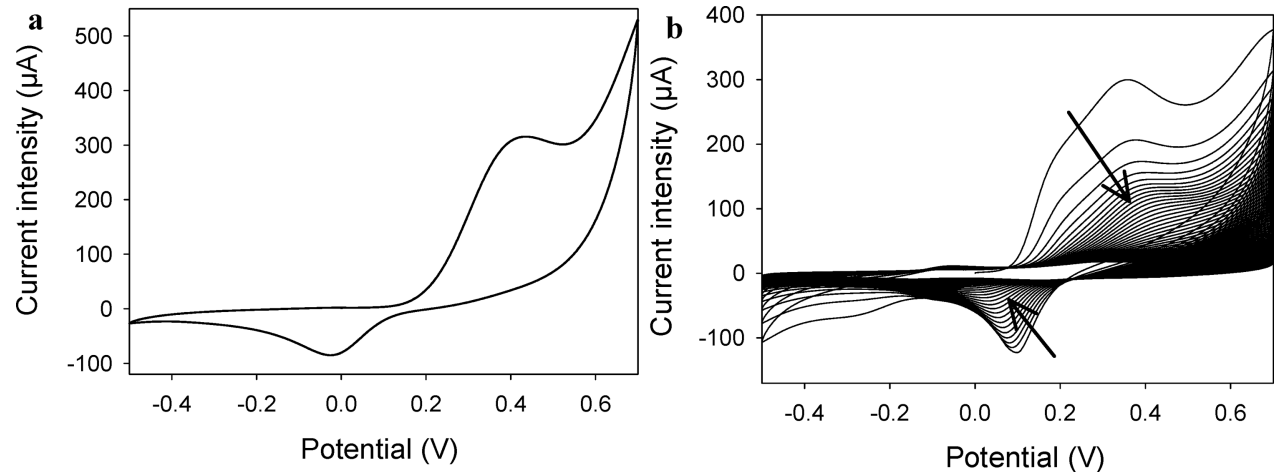

Figure 2. Cyclic voltamograms with (a) 1 cycle of bis-catechol $(1 \mathrm{mg} / \mathrm{mL})$ solution and (b) 180 cycles $(1 \mathrm{~h}, 20$ s between each cycle) of bis-catechol $(1 \mathrm{mg} / \mathrm{mL})$ and $\mathrm{PAH}(1 \mathrm{mg} / \mathrm{mL})$ mixture solution (catechol/amine ratio of 0.38 ) over the potential range of $-0.5 \mathrm{to} 0.7 \mathrm{~V}$ (vs $\mathrm{Ag} / \mathrm{AgCl}, \mathrm{scan}$ rate $50 \mathrm{mV} / \mathrm{s}$ ). The supporting electrolyte was $10 \mathrm{mM}$ Hepes-150 $\mathrm{mM} \mathrm{NaNO}_{3}$ buffer solution at $\mathrm{pH}$ 7.4.

Scheme 2. Schematic Representation of the Two Chemical Steps of the Self-Construction Buildup Leading to Covalent Crosslinking between PAH and Bis-Catechol

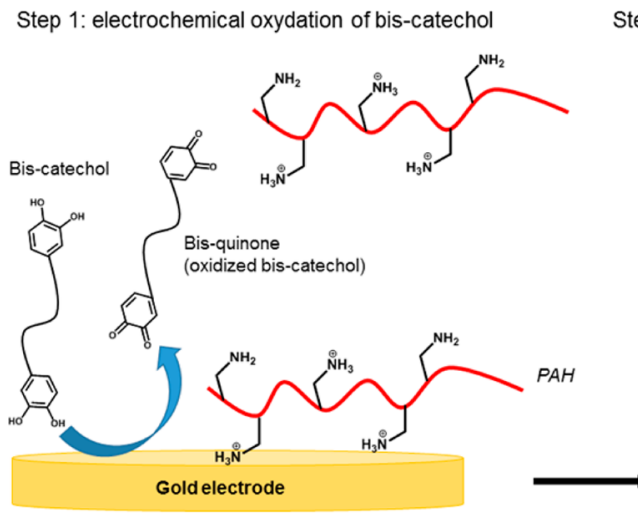

Step 2: covalent crosslinking between PAH and bis-catecho

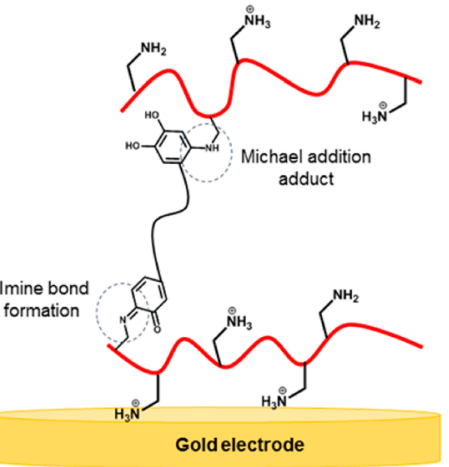

\section{RESULTS AND DISCUSSION}

Electro-Triggered Self-Construction of PAH/Bis-Catechol Films. We first investigated the electrochemical response of bis-catechol molecules (Figure 2a) by cyclic voltammetry. A couple of redox peaks can be observed which corresponds to the transformation of catechols to quinones and vice versa (see Scheme 2 step 1).

The oxidation and reduction peaks are, respectively, at $0.4 \mathrm{~V}$ and $-0.03 \mathrm{~V}(\mathrm{vs} \mathrm{Ag} / \mathrm{AgCl})$. This is in good accordance with the literature. ${ }^{28-30}$

The self-construction of PAH and bis-catechol films was studied by EC-QCM allowing us to follow in situ the buildup of the film during the application of the electrical stimulus. PAH and bis-catechol mixtures were prepared in $10 \mathrm{mM}$ HEPES$150 \mathrm{mM} \mathrm{NaNO}$ aqueous buffer at $\mathrm{pH}$ 7.4. The HEPES buffer compensates the production of $\mathrm{H}^{+}$from oxidation of catechol into quinone. Indeed quinone moieties cannot react with amine functions in acidic conditions. Figure 3 shows a typical QCM signal relative to the buildup obtained with a catechol/amine ratio of 0.38 (molar ratio of each chemical group). After injection of the $\mathrm{PAH} /$ bis-catechol mixture, a small increase of the normalized frequency is observed due to PAH electrostatic adsorption (polycation) and coordination bonding between catechol and gold. The application of cyclic voltammetry (CV) between 0 and $500 \mathrm{mV}$ (vs $\mathrm{Ag} / \mathrm{AgCl}$, scan rate of $50 \mathrm{mV} / \mathrm{s}$ ) results in a fast increase of the normalized frequency shift reaching a plateau at $1100 \mathrm{~Hz}$ after $80 \mathrm{~min}$.

Figure $2 \mathrm{~b}$ represents the evolution of the electrochemical signal during the self-construction of a PAH/bis-catechol film.

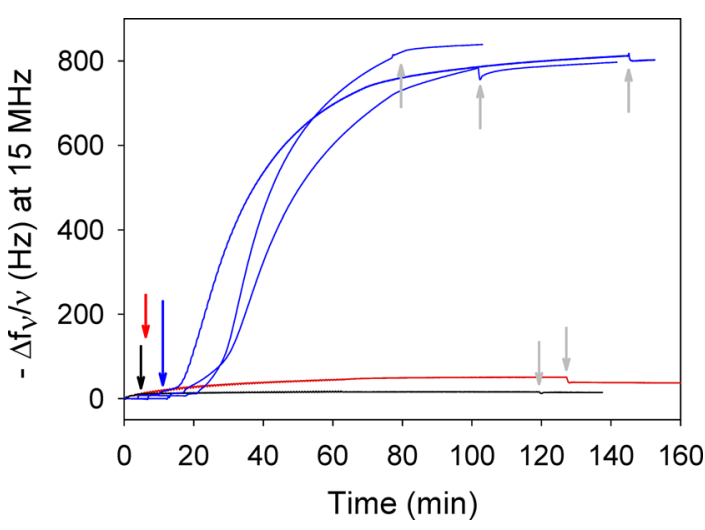

Figure 3. Evolution of the normalized frequency shift, measured by EC-QCM, as a function of time of (blue lines) $\mathrm{PAH} /$ bis-catechol mixture ( 0.38 in catechol/amine molar ratio), (red line) bis-catechol, and (black line) PAH solutions during the application of CV between 0 and $+500 \mathrm{mV}$ (vs Ag/AgCl, scan rate $50 \mathrm{mV} / \mathrm{s}$ ). After injection of the solutions, $\mathrm{CV}$ was applied as indicated by the respective colored arrow. The gray arrows correspond to the end of CV application.

The oxidation currents decrease with the number of cycles to reach the capacitive current after 30 cycles. At the first cycle, the oxidation and reduction peaks of bis-catechol are at 0.37 and $0.10 \mathrm{~V}$, respectively. The oxidation peak shifts during the selfconstruction toward positive values while the reduction peak shifts toward the negative value (Figure S-2). The overall apparent redox potential, $E_{1 / 2}=1 / 2\left(E_{\mathrm{ox}}^{\mathrm{p}}+E_{\mathrm{red}}^{\mathrm{p}}\right)$, shifts toward more positive values (Figure S-3). This may be due to the 

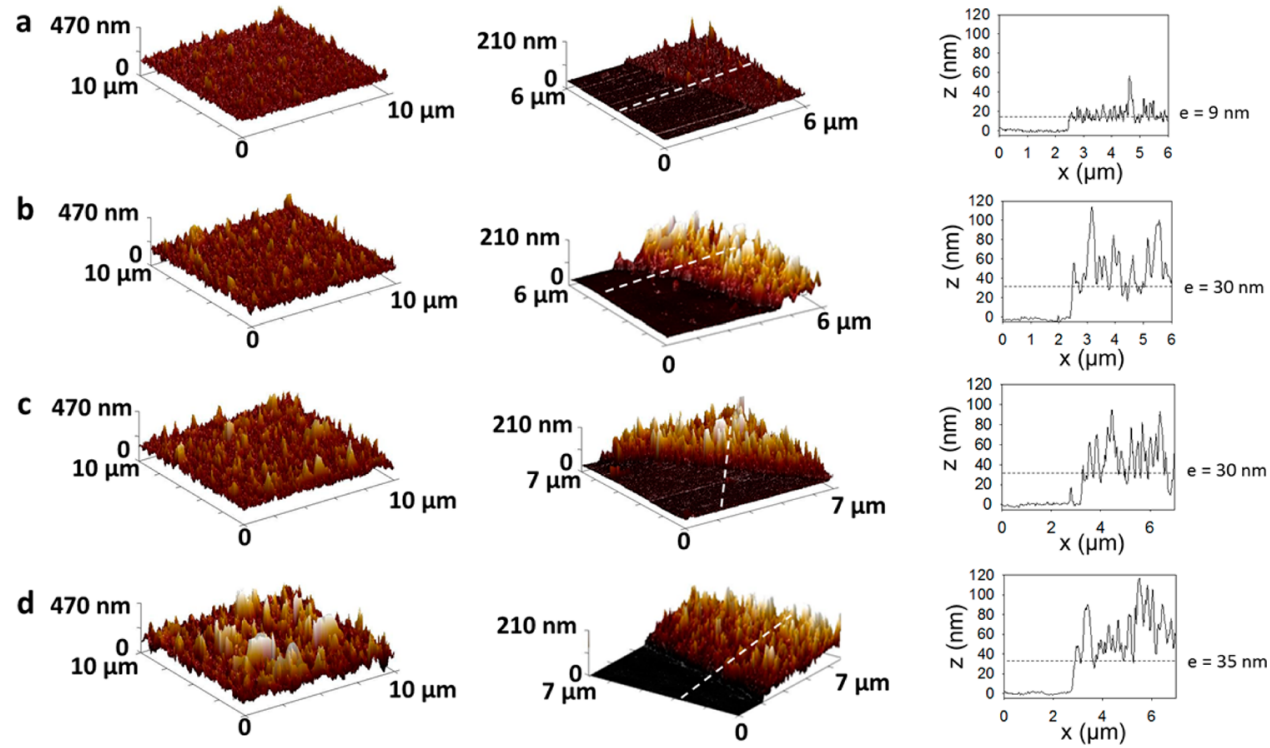

Figure 4. Typical AFM 3D images, obtained in contact mode (liquid state), and their respective cross-section profiles of a scratched PAH/biscatechol film, obtained after (a) $5 \mathrm{~min}$, (b) $10 \mathrm{~min}$, (c) $20 \mathrm{~min}$, and (d) $60 \mathrm{~min}$ of self-construction. The film buildup was performed with PAH/biscatechol solution at 0.38 in catechol/amine molar ratio by applying a CV between 0 and $+500 \mathrm{mV}$ (vs $\mathrm{Ag} / \mathrm{AgCl}, \mathrm{scan}$ rate $50 \mathrm{mV} / \mathrm{s}$ ). The white dashed-lines show the lines corresponding to the profiles presented on the right.
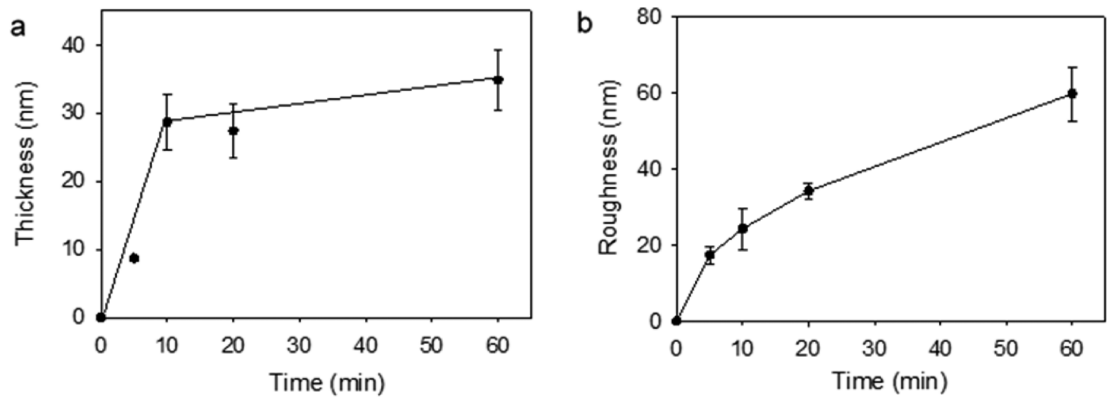

Figure 5. Evolution of the thickness and the roughness, measured by AFM in contact mode and liquid state, as a function of time of the selfconstructed film obtained from a PAH/bis-catechol mixture solution at 0.38 in catechol/amine ratio by applying a CV between 0 and $+500 \mathrm{mV}$ (vs $\mathrm{Ag} / \mathrm{AgCl}$, scan rate $50 \mathrm{mV} / \mathrm{s}$ ). The roughness was calculated on a $10 \mu \mathrm{m} \times 10 \mu \mathrm{m} \mathrm{AFM} \mathrm{images.}$

Donnan potential in the film generated by the positive charges from PAH. ${ }^{31}$ The decrease of the current intensity during film construction must originate from the increased limitation of the bis-catechol to diffuse toward the electrode as build up proceeds. This then prevents further oxidation of catechols into quinones, hindering further film buildup. When a $\mathrm{PAH}$ solution is used with the same self-construction setup, the QCM signal remains stable (Figure 3). In the case of a biscatechol solution, a small increase of the frequency shift is observed until $130 \mathrm{~Hz}$ after $2 \mathrm{~h}$ of CV application. This could be due to a polymerization reaction of bis-catechol as already observed in the literature for catechol-derived compounds. ${ }^{32,33}$ Poly(diallyldimethylammonium chloride) (PDADMA) is a polycation bearing only quarternary amines which cannot react with quinones. When PAH is replaced by PDADMA in the mixture solution keeping the same catechol/amine ratio, no buildup occurs (Figure S-1 in the Supporting Information). These different control experiments prove that the increase of the QCM signal in the simultaneous presence of PAH and biscatechol molecules is due to a chemical reaction between both components.

AFM Characterization of Self-Constructed PAH/BisCatechol Films. AFM measurements were performed in contact mode and liquid state to characterize the topography of the self-constructed films and also their thicknesses after scratching (Figure 4).

Figure 5 shows the evolution of the film thickness (minimal $z$ distance between the bare substrate and the surface of the film for which the whole substrate is covered) measured by AFM at different times. After $5 \mathrm{~min}$ of $\mathrm{CV}$ application, the $\mathrm{PAH} /$ biscatechol film covers uniformly the whole substrate with a thickness of $9 \mathrm{~nm}$. The film thickness increases as a function of the application time of the $\mathrm{CV}$, reaching $35 \mathrm{~nm}$ after $60 \mathrm{~min}$ of self-construction. One can notice that the thickness of the film increases in the same manner as the normalized frequency shift, i.e., a high increase during the first $15 \mathrm{~min}$ of self-construction followed by a much slower increase. One can also remark that the films are quite rough and that the roughness increases during the film buildup process (Figure $5 \mathrm{~b}$ ). Interestingly similarly rough films, corresponding to the presence of a large number of spikes, were obtained for other electrochemically triggered morphogen film buildup examples which involve one component which is a small bis-functionalized molecules. ${ }^{22,34}$ It is thus tempting to correlate this spiky structure with the use of bis-functional ethylene glycol spacers. 
a

.

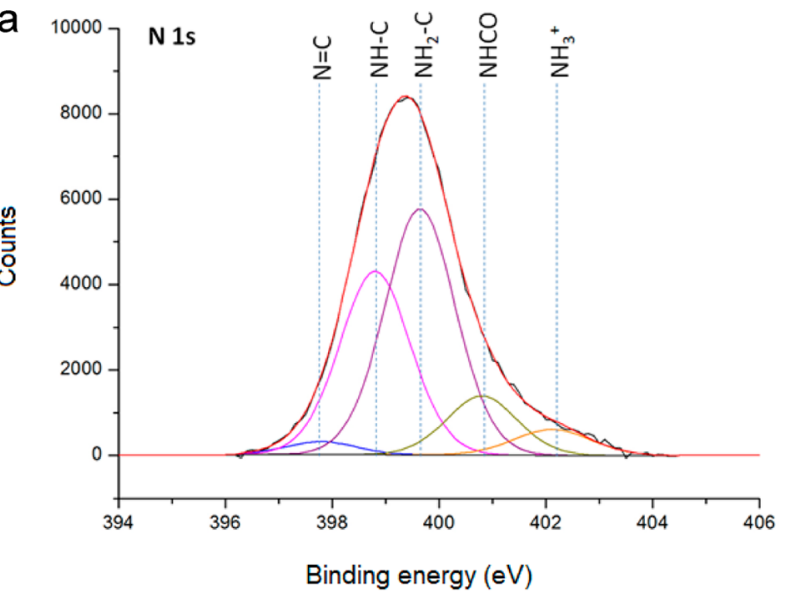

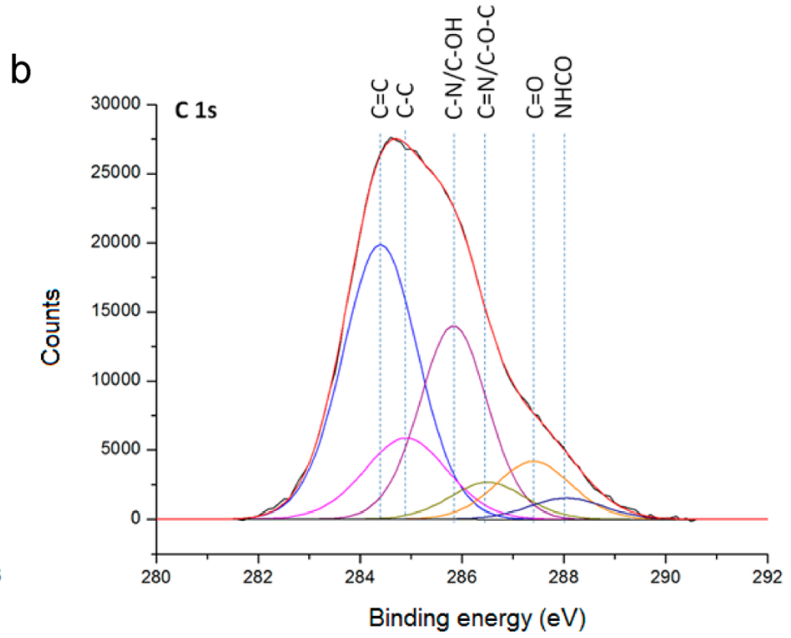

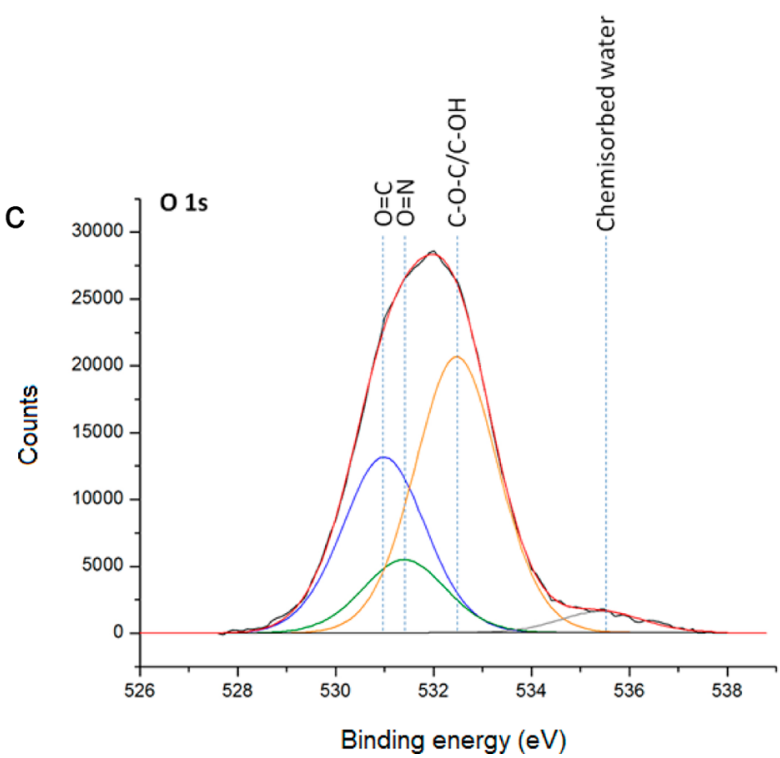

Figure 6. High-resolution XPS spectra of (a) N 1s, (b) C 1s, and (c) O 1s regions of a self-constructed film obtained from a PAH/bis-catechol solution at $0.19 \mathrm{in} \mathrm{catechol/amine} \mathrm{molar} \mathrm{ratio} \mathrm{by} \mathrm{applying} \mathrm{a} \mathrm{CV}$ between 0 and $+500 \mathrm{mV}$ (vs $\mathrm{Ag} / \mathrm{AgCl}$, scan rate $50 \mathrm{mV} / \mathrm{s}$ ) for $60 \mathrm{~min}$.

\section{Table 1. XPS Peak Binding Energy Assignments and Corresponding References}

\begin{tabular}{|c|c|c|c|}
\hline atom (chemical group) & binding energy $(\mathrm{eV})$ & binding energy in litt. $(\mathrm{eV})$ & refs \\
\hline $\mathrm{O}=\mathrm{C}$ (quinone) & 531.0 & $531.0 \pm 0.2$ & 35,37 \\
\hline $\mathrm{O}=\mathrm{C}($ amide $)$ & 531.4 & 531.6 & 38 \\
\hline $\mathrm{O}-\mathrm{C}$ & 532.5 & 532.6 & 39 \\
\hline $\mathbf{O}$ of chemisorbed water & 535.4 & 535.9 & 40 \\
\hline $\mathbf{N}=\mathrm{C}$ (imine) & 397.8 & $397.8-399.0$ & $35,37,41$ \\
\hline $\mathrm{NH}-\mathrm{C}$ & 398.8 & 398.8 & 37 \\
\hline $\mathrm{NH}_{2}-\mathrm{C}$ & 399.6 & $399.1-399.6$ & 42 \\
\hline NHCO (amide) & 400.6 & $400.5-400.7$ & 43 \\
\hline $\mathrm{NH}_{3}^{+}$(ammonium) & 402.0 & 401.8 & 43 \\
\hline $\mathrm{C}=\mathrm{C}$ (aromatic) & 284.4 & $284.0-284.3$ & 44 \\
\hline C-C (aliphatic) & 284.9 & $284.5-285.1$ & 44 \\
\hline \multirow[t]{2}{*}{$\mathrm{C}-\mathrm{N}$ (amine) and $\mathrm{C}_{\text {aromatic }}-\mathrm{OH}$ (phenol) } & 285.5 & $285.4-286(\mathrm{C}-\mathrm{N})$ & 35,45 \\
\hline & & $285.8 \pm 0.1\left(\mathrm{C}_{\text {aromatic }}-\mathrm{OH}\right)$ & 37 \\
\hline \multirow[t]{2}{*}{$\mathrm{C}=\mathrm{N}$ (imine) and $\mathrm{C}-\mathrm{O}-\mathrm{C}$ (ether) } & 286.5 & 286.5-286.7 $(\mathrm{C}=\mathrm{N}$, imine $)$ & 42,45 \\
\hline & & $286.2-286.7(\mathrm{C}-\mathrm{O}-\mathrm{C}$, ether $)$ & 46 \\
\hline $\mathrm{C}=\mathrm{O}$ (quinone) & 287.4 & $287.7 \pm 0.4$ & $35,37,42$ \\
\hline NHCO (amide) & 288.0 & $287.9-288.3$ & $45-47$ \\
\hline
\end{tabular}

Chemical Analysis of the Self-Constructed PAH/BisCatechol Films. XPS analysis provides chemical information about the atomic and the chemical group composition of surface coating. Such analysis has been recently reported for 

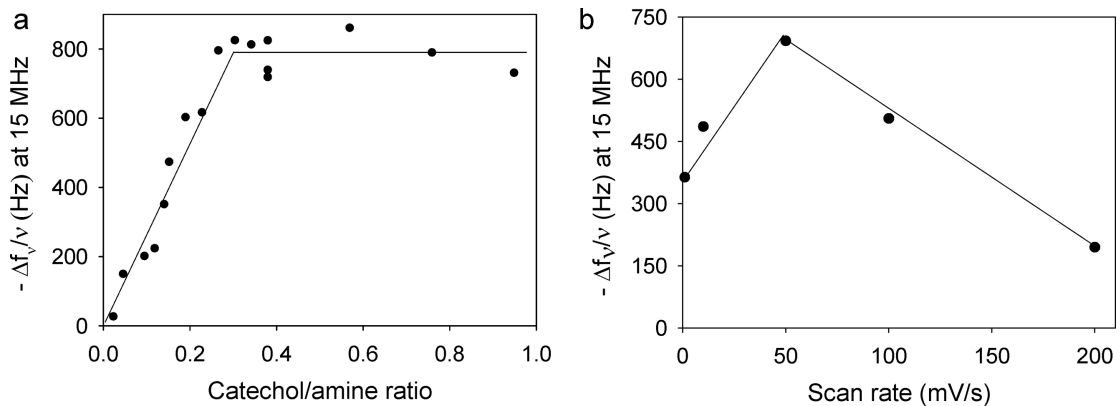

Figure 7. (a) Evolution of the normalized frequency shift of a PAH/bis-catechol mixture, obtained after 60 min of CV application between 0 and $+500 \mathrm{mV}$ (vs Ag/AgCl, scan rate $50 \mathrm{mV} / \mathrm{s}$ ), as a function of catechol/amine ratio. (b) Evolution of the normalized frequency shift of a PAH/biscatechol mixture (at 0.23 in catechol/amine ratio), obtained after $60 \mathrm{~min}$ of $\mathrm{CV}$ application between 0 and $+500 \mathrm{mV}(\mathrm{vs} \mathrm{Ag} / \mathrm{AgCl})$ as a function of the scan rate. The lowest scan rate corresponds to $1 \mathrm{mV} / \mathrm{s}$.

bioinspired coatings based on catecholamine derivatives. ${ }^{35,36} \mathrm{~A}$ film self-constructed for $60 \mathrm{~min}$ from $\mathrm{PAH}$ and bis-catechol according to parameters described in the Materials and Methods section (described above) has been analyzed by XPS. Representative high-resolution spectra of $\mathrm{N} \mathrm{1s,} \mathrm{C} \mathrm{1s,} \mathrm{and}$ $\mathrm{O}$ 1s regions of this film are shown in Figure 6. The energies and chemical group assignment for each measured peak are listed in Table 1 and are similar to the values reported in the literature. In some cases, there is an overlap of peaks corresponding to atoms involved in several chemical groups. To avoid wrong conclusions we did not calculate any percent contribution coming from the decomposition of the experimental peaks.

As depicted in Figure 1 and Scheme 2, nitrogen atoms can come from uncharged primary amine $\mathrm{NH}_{2}$, from ammonium $\mathrm{NH}_{3}{ }^{+}$groups both related to $\mathrm{PAH}$, from secondary amines resulting from the Michael addition from the imines originating from the Schiff's base condensation reaction and from the amide bonds $(\mathrm{NHC}=\mathrm{O})$ of the bis-catechol molecules. The $\mathrm{N}$ 1s region was thus fitted with five peaks assigned to nitrogen involved in imine $(\mathrm{N}=\mathrm{C})$, secondary and primary amines $\left(\mathbf{N H}-\mathrm{C} / \mathrm{NH}_{2}-\mathrm{C}\right)$, amide $(\mathbf{N H C}=\mathrm{O})$, and ammonium $\left(\mathrm{NH}_{3}{ }^{+}\right)$groups. All these peaks seem to be present in the $\mathrm{N}(1 \mathrm{~s})$ band even if the contribution of the peak relative to the imines appears rather small. On the other hand the strong contribution of the secondary amine peak indicates that the catechols have reacted with the amines of PAH through Michael addition (Scheme 2). Moreover the presence of the primary amine and of the amide peaks confirms the presence of both PAH and of the bis-catechol molecules in the film. In addition, five others peak energies observed in the $\mathrm{C} 1 \mathrm{~s}$ region are assigned to $\mathrm{C}-\mathrm{C}$ aromatic, $\mathbf{C}-\mathrm{C}$ aliphatic, $\mathrm{C}-\mathrm{N} / \mathrm{C}-\mathrm{OH}$ aromatic (overlapped), $\mathrm{C}=\mathrm{O}$ (quinone), and $\mathrm{NHCO}$, confirming again the presence of both $\mathrm{PAH}$ and bis-catechol in the self-constructed film. Oxygen atoms come exclusively from catechol or oxidized catechol (quinone) molecules present in the film. Catechols are composed of two types of oxygen atoms: one coming from the catechol phenolic hydroxyls and ether groups ( $\mathrm{C}-\mathrm{O}$ simple bond) and the other one involved in the amide bonds $(\mathrm{NHC}=\mathrm{O})$. The $\mathrm{O} 1 \mathrm{~s}$ peak was thus fitted by using four peaks assigned to $\mathbf{O}-\mathrm{C}, \mathrm{O}=$ $\mathrm{C}$ (quinone, i.e., oxidized catechol), $\mathrm{O}=\mathrm{CNH}$, and the oxygen coming from chemisorbed water. The presence of quinone $(\mathrm{O}=\mathrm{C})$ comes from the oxidation of catechols into quinone occurring during the electrochemical film buildup. They remain present in the self-constructed film as in the case of catecholamine derivatives polymerization leading to a high proportion of stable quinone groups. ${ }^{35,36}$ This presence of quinones is in agreement with our proposed model of a selfconstructed film based on catechol oxidation. In summary, the XPS analysis of the self-constructed film reveals the presence of both PAH and bis-catechol covalently linked through secondary amines formation. The presence of quinone groups, resulting from the electro-oxidation of bis-catechol molecules in the close vicinity of the electrode and highlights the concept of morphogens (i.e., oxidized bis-catechol) allowing the selfconstruction of the film.

Influence of the Physicochemical Conditions on the Self-Construction. The influence of catechol/amine ratio of the PAH/bis-catechol mixture was first studied. According to the conditions previously described, the mixtures were prepared at $1 \mathrm{mg} / \mathrm{mL}$ in $\mathrm{PAH}$ and bis-catechol corresponding to a catechol/amine molar ratio of 0.38 . Keeping the PAH concentration constant, the bis-catechol concentration was tuned from 0.06 to $2.5 \mathrm{mg} / \mathrm{mL}$, corresponding to catechol/ amine molar ratios ranging from 0.02 to 0.95 . Figure $7 \mathrm{a}$ represents the normalized frequency shift obtained after $60 \mathrm{~min}$ of self-construction at each studied ratio. The mass deposited increases linearly with the catechol/amine ratio until it reaches a plateau at a ratio of 0.3 . This corresponds approximatively to seven amine functions from PAH for one bis-catechol molecule, i.e., seven amine functions for two catechol groups. Above a ratio of 0.3 , no change of the buildup kinetic is observed. The limited buildup is thus probably due to the fact that the film becomes dense and that the bis-catechol molecules can no longer diffuse through. This is also suggested by the evolution of the current intensity during the film buildup (Figure $2 b$ ).

The influence of the scan rate of the $\mathrm{CV}$ was also investigated (Figure S-4 in the Supporting Information). The $50 \mathrm{mV} / \mathrm{s}$ in scan rate was applied in all the results reported so far. Figure $7 \mathrm{~b}$ shows the normalized frequency shift obtained after $60 \mathrm{~min}$ of self-construction for the different scan rates at a fixed catechol/ amine ratio of 0.23 . Figure $\mathrm{S}-5-\mathrm{S}-7$ in the Supporting Information shows the evolution of the normalized frequency shifts and of the potential during the application of the first four potential-cycles at 1,50 , and $100 \mathrm{mV} / \mathrm{s}$ in scan rate, respectively. By decreasing the scan rate from $50 \mathrm{mV} / \mathrm{s}$ to 1 $\mathrm{mV} / \mathrm{s}$, the mass deposited decreases. Likewise, when the scan rate increases to $200 \mathrm{mV} / \mathrm{s}$ the mass deposited decreases. An optimum of the buildup is obtained for a scan rate of $50 \mathrm{mV} / \mathrm{s}$. The existence of an optimum scan rate in the film buildup reflects the fact that the buildup process must be governed by at least two antagonistic effects. During a CV cycle, catechol molecules near the electrode are oxidized into quinones during 
the period of the cycle corresponding to oxidation conditions. These quinones can be reduced back into catechols during the time of the cycle which corresponds to reduction conditions. At a slow scan rate, during one cycle both the oxidation and reductions periods are long. Large amount of oxidized molecules are formed before reduction of these molecules takes place. Therefore, it can be assumed that at slow scan rates one forms dense films near the electrode. Because they are dense, the films rapidly reduce the diffusion of further biscatechol molecules through. On the other hand, at very high scan rates, the each oxidation period is rapidly followed by a reduction period. The oxidized quinone molecules are then rapidly reduced back into their catechol "nonactive" form. Thus, the flux of quinone molecules diffusing toward the solution, responsible for the interaction with $\mathrm{PAH}$ and for the formation of the film, would become small. In the limit of a very small flux, no film would form. Indeed, the rare catechol molecules that would diffuse into the solution would react with PAH chains without being able to form a network. There must thus exist an intermediate scan rate where the flux of quinones is sufficient to form efficiently a network with the PAH chains, forming a film that is not very dense at the beginning and thus allowing diffusion of catechol molecules through. Such a film will thus reach a thickness that is larger than at very low scan rates and of course larger than what is expected at very high scan rates. Yet as the buildup process goes on, the catechol molecules continue also to interact with the PAH chains near the electrode. This film becomes thus also denser with time and correlatively the diffusion of catechol molecules through is reduced. After a while this diffusion is hindered and the film buildup stops. This tentative explanation needs a whole physicochemical study to be fully validated but this is out of the scope of this article whose aim was to demonstrate the possibility to build an electrochemically triggered film construction with polyamines and bis-catechol molecules.

\section{CONCLUSIONS}

We designed a catechol based electrochemically triggered construction of films based on an organic morphogen, biscatechol. By CV application, the oxidized bis-catechol spacers react with $\mathrm{PAH}$ forming a polymeric film that self-constructed exclusively on the surface of the electrode. A fast buildup is obtained that reaches a plateau after $20 \mathrm{~min}$. These films present a spiky structure. This is attributed to the use of bifunctional molecules as a film constituent. We show that the amine/catechol ratio is an important parameter which governs the film buildup. For a given amine/catechol ratio there exists an optimum $\mathrm{CV}$ scan rate leading to a maximum of the film thickness as a function of the scan rate. We are now working to extend this method to protein/bis-catechol electrotriggered film construction that could be of interest for biosensor design.

\section{ASSOCIATED CONTENT}

\section{S Supporting Information}

The Supporting Information is available free of charge on the ACS Publications website at DOI: 10.1021/acs.langmuir.5b03774.

Detailed synthesis of bis-catechol, EC-QCM control experiment with PDADMA/bis-catechol mixture, electrochemistry and EC-QCM experiment with $\mathrm{PAH} /$ biscatechol at 1,50 , and $100 \mathrm{mV} / \mathrm{s}$ in scan rate (PDF)

\section{AUTHOR INFORMATION}

\section{Corresponding Authors}

*E-mail: loic.jierry@ics-cnrs.unistra.fr. Phone: +33-3-88-41-4147.

*E-mail: fouzia.boulmedais@ics-cnrs.unistra.fr. Phone: +33-388-41-41-60.

\section{Author Contributions}

The manuscript was written through contributions of all authors. All authors have given approval to the final version of the manuscript.

\section{Notes}

The authors declare no competing financial interest.

\section{ACKNOWLEDGMENTS}

C.M. was supported by a fellowship from the "Ministère de la Recherche et de la Technologie”. T.G. was supported by a postdoctoral fellowship from Labex "Chimie des Systèmes Complexes” (Labex CSC) and from International Center for Frontier Research in Chemistry (icFRC). N.T.T.C was supported by a post-doctoral fellowship from University of Strasbourg Institute for Advanced Study (USIAS). The authors gratefully acknowledge financial support from Agence Nationale de la Recherche (ANR JCJC Morphobuildup, Grant ANR13-JS08-0003-01) USIAS, and IUF.

\section{REFERENCES}

(1) Waite, J. H.; Tanzer, M. L. Polyphenolic Substance of MytilusEdulis - Novel Adhesive Containing L-Dopa and Hydroxyproline. Science 1981, 212, 1038-1040.

(2) Waite, J. H. Nature's Underwater Adhesive Specialist. Int. J. Adhes. Adhes. 1987, 7, 9.

(3) Lee, H.; Dellatore, S. M.; Miller, W. M.; Messersmith, P. B. Mussel-Inspired Surface Chemistry for Multifunctional Coatings. Science 2007, 318, 426-430.

(4) Lee, B. P.; Messersmith, P. B.; Israelachvili, J. N.; Waite, J. H.; Clarke, D. R.; Fratzl, P. Annu. Rev. Mater. Res. 2011, 41, 99-132.

(5) Sedo, J.; Saiz-Poseu, J.; Busque, F.; Ruiz-Molina, D. CatecholBased Biomimetic Functional Materials. Adv. Mater. 2013, 25, 653701.

(6) Faure, E.; Falentin-Daudre, C.; Jerome, C.; Lyskawa, J.; Fournier, D.; Woisel, P.; Detrembleur, C. Catechols as Versatile Platforms in Polymer Chemistry. Prog. Polym. Sci. 2013, 38, 236-270.

(7) Krylova, I. Painting by Electrodeposition on the Eve of the 21st Century. Prog. Org. Coat. 2001, 42, 119-131.

(8) Wu, L. Q.; Gadre, A. P.; Yi, H. M.; Kastantin, M. J.; Rubloff, G. W.; Bentley, W. E.; Payne, G. F.; Ghodssi, R. Voltage-Dependent Assembly of the Polysaccharide Chitosan onto an Electrode Surface. Langmuir 2002, 18, 8620-8625.

(9) Boccaccini, A. R.; Keim, S.; Ma, R.; Li, Y.; Zhitomirsky, I. Electrophoretic Deposition of Biomaterials. J. R. Soc., Interface 2010, 7, S581-S613.

(10) Ngankam, A. P.; Van Tassel, P. R. Continuous Polyelectrolyte Adsorption under an Applied Electric Potential. Proc. Natl. Acad. Sci. U. S. A. 2007, 104, 1140-1145.

(11) Olsen, C.; Van Tassel, P. R. Polyelectrolyte Adsorption Kinetics under an Applied Electric Potential: Strongly Versus Weakly Charged Polymers. J. Colloid Interface Sci. 2009, 329, 222-227.

(12) Shi, X. W.; Tsao, C. Y.; Yang, X. H.; Liu, Y.; Dykstra, P.; Rubloff, G. W.; Ghodssi, R.; Bentley, W. E.; Payne, G. F. Electroaddressing of Cell Populations by Co-Deposition with Calcium Alginate Hydrogels. Adv. Funct. Mater. 2009, 19, 2074-2080.

(13) Cheng, Y.; Tsao, C. Y.; Wu, H. C.; Luo, X. L.; Terrell, J. L.; Betz, J.; Payne, G. F.; Bentley, W. E.; Rubloff, G. W. Electroaddressing Functionalized Polysaccharides as Model Biofilms for Interrogating Cell Signaling. Adv. Funct. Mater. 2012, 22, 519-528. 
(14) Johnson, E. K.; Adams, D. J.; Cameron, P. J. Directed SelfAssembly of Dipeptides to Form Ultrathin Hydrogel Membranes. J. Am. Chem. Soc. 2010, 132, 5130-5136.

(15) Liu, Y.; Cheng, Y.; Wu, H. C.; Kim, E.; Ulijn, R. V.; Rubloff, G. W.; Bentley, W. E.; Payne, G. F. Electroaddressing Agarose Using Fmoc-Phenylalanine as a Temporary Scaffold. Langmuir 2011, 27, $7380-7384$

(16) Leisk, G. G.; Lo, T. J.; Yucel, T.; Lu, Q.; Kaplan, D. L. Electrogelation for Protein Adhesives. Adv. Mater. 2010, 22, 711-715.

(17) Wong, I. Y.; Footer, M. J.; Melosh, N. A. Electronically Activated Actin Protein Polymerization and Alignment. J. Am. Chem. Soc. 2008, 130, 7908-7915.

(18) Waltman, R. J.; Bargon, J. Electrically Conducting Polymers - a Review of the Electropolymerization Reaction, of the Effects of Chemical-Structure on Polymer Film Properties, and of Applications Towards Technology. Can. J. Chem. 1986, 64, 76-95.

(19) Rydzek, G.; Jierry, L.; Parat, A.; Thomann, J. S.; Voegel, J. C.; Senger, B.; Hemmerle, J.; Ponche, A.; Frisch, B.; Schaaf, P.; Boulmedais, F. Electrochemically Triggered Assembly of Films: A One-Pot Morphogen-Driven Buildup. Angew. Chem., Int. Ed. 2011, 50, 4374-4377.

(20) Rydzek, G.; Garnier, T.; Schaaf, P.; Voegel, J. C.; Senger, B.; Frisch, B.; Haikel, Y.; Petit, C.; Schlatter, G.; Jierry, L.; Boulmedais, F. Self-Construction of Supramolecular Polyrotaxane Films by an Electrotriggered Morphogen-Driven Process. Langmuir 2013, 29, 10776-10784.

(21) Rydzek, G.; Parat, A.; Polavarapu, P.; Baehr, C.; Voegel, J. C.; Hemmerle, J.; Senger, B.; Frisch, B.; Schaaf, P.; Jierry, L.; Boulmedais, F. One-Pot Morphogen Driven Self-Constructing Films Based on Non-Covalent Host-Guest Interactions. Soft Matter 2012, 8, 446-453.

(22) Rydzek, G.; Polavarapu, P.; Rios, C.; Tisserant, J. N.; Voegel, J. C.; Senger, B.; Lavalle, P.; Frisch, B.; Schaaf, P.; Boulmedais, F.; Jierry, L. Morphogen-Driven Self-Construction of Covalent Films Built from Polyelectrolytes and Homobifunctional Spacers: Buildup and $\mathrm{Ph}$ Response. Soft Matter 2012, 8, 10336-10343.

(23) Rydzek, G.; Terentyeva, T. G.; Pakdel, A.; Golberg, D.; Hill, J. P.; Ariga, K. Simultaneous Electropolymerization and Electro-Click Functionalization for Highly Versatile Surface Platforms. ACS Nano 2014, 8, 5240-5248.

(24) Turing, A. M. The Chemical Basis of Morphogenesis. Philos. Trans. R. Soc., B 1952, 237, 37-72.

(25) Potter, J. D. Morphogens, Morphostats, Microarchitecture and Malignancy. Nat. Rev. Cancer 2007, 7, 464-474.

(26) Gray, K. M.; Liba, B. D.; Wang, Y. F.; Cheng, Y.; Rubloff, G. W.; Bentley, W. E.; Montembault, A.; Royaud, I.; David, L.; Payne, G. F. Electrodeposition of a Biopolymeric Hydrogel: Potential for One-Step Protein Electroaddressing. Biomacromolecules 2012, 13, 1181-1189.

(27) Cai, W. B.; Kwok, S. W.; Taulane, J. P.; Goodman, M. MetalAssisted Assembly and Stabilization of Collagen-Like Triple Helices. J. Am. Chem. Soc. 2004, 126, 15030-15031.

(28) Tian, Y. A.; Ye, S. Q.; Ran, Q.; Xian, Y. Z.; Xu, J. J.; Peng, R.; Jin, L. T. Generation of Surface-Confined Catechol Terminated Sams Via Electrochemically Triggered Michael Addition: Characterization, Electrochemistry and Complex with $\mathrm{Ni}(\mathrm{Ii})$ and $\mathrm{Cu}(\mathrm{Ii})$ Cations. Phys. Chem. Chem. Phys. 2010, 12, 13287-13295.

(29) Apetrei, C.; de Saja, J. A.; Zurro, J.; Rodriguez-Mendez, M. L. Advantages of the Biomimetic Nanostructured Films as an Immobilization Method Vs. The Carbon Paste Classical Method. Catalysts 2012, 2, 517-531.

(30) Lakshmi, D.; Bossi, A.; Whitcombe, M. J.; Chianella, I.; Fowler, S. A.; Subrahmanyam, S.; Piletska, E. V.; Piletsky, S. A. Electrochemical Sensor for Catechol and Dopamine Based on a Catalytic Molecularly Imprinted Polymer-Conducting Polymer Hybrid Recognition Element. Anal. Chem. 2009, 81, 3576-3584.

(31) El Haitami, A. E.; Martel, D.; Ball, V.; Nguyen, H. C.; Gonthier, E.; Labbe, P.; Voegel, J.-C.; Schaaf, P.; Senger, B.; Boulmedais, F. Effect of the Supporting Electrolyte Anion on the Thickness of Pss/ Pah Multilayer Films and on Their Permeability to an Electroactive Probe. Langmuir 2009, 25, 2282-2289.
(32) Kong, Y.; Mu, S. L. Investigation on the Electrochemical Polymerization of Catechol by Means of Rotating Ring-Disk Electrode. Chin. J. Chem. 2003, 21, 630-637.

(33) Marczewska, B.; Przegalinski, M. Poly(Catechol) Electroactive Film and Its Electrochemical Properties. Synth. Met. 2013, 182, 33-39.

(34) El Haitami, A. E.; Thomann, J. S.; Jierry, L.; Parat, A.; Voegel, J. C.; Schaaf, P.; Senger, B.; Boulmedais, F.; Frisch, B. Covalent Layerby-Layer Assemblies of Polyelectrolytes and Homobifunctional Spacers. Langmuir 2010, 26, 12351-12357.

(35) Zangmeister, R. A.; Morris, T. A.; Tarlov, M. J. Characterization of Polydopamine Thin Films Deposited at Short Times by Autoxidation of Dopamine. Langmuir 2013, 29, 8619-8628.

(36) Bernsmann, F.; Ponche, A.; Ringwald, C.; Hemmerle, J.; Raya, J.; Bechinger, B.; Voegel, J. C.; Schaaf, P.; Ball, V. Characterization of Dopamine-Melanin Growth on Silicon Oxide. J. Phys. Chem. C 2009, $113,8234-8242$.

(37) Wang, Z.; Sun, C. Y.; Vegesna, G.; Liu, H. Y.; Liu, Y.; Li, J. H.; Zeng, X. Q. Glycosylated Aniline Polymer Sensor: Amine to Imine Conversion on Protein-Carbohydrate Binding. Biosens. Bioelectron. 2013, 46, 183-189.

(38) Amaral, I. F.; Granja, P. L.; Barbosa, M. A. Chemical Modification of Chitosan by Phosphorylation: An Xps, Ft-Ir and Sem Study. J. Biomater. Sci., Polym. Ed. 2005, 16, 1575-1593.

(39) Rosenthal, D.; Ruta, M.; Schlogl, R.; Kiwi-Minsker, L. Combined Xps and Tpd Study of Oxygen-Functionalized Carbon Nanofibers Grown on Sintered Metal Fibers. Carbon 2010, 48, 18351843.

(40) Figueiredo, J. L.; Pereira, M. F. R.; Freitas, M. M. A.; Orfao, J. J. M. Modification of the Surface Chemistry of Activated Carbons. Carbon 1999, 37, 1379-1389.

(41) Ando, R. A.; do Nascimento, G. M.; Landers, R.; Santos, P. S. Spectroscopic Investigation of Conjugated Polymers Derived from Nitroanilines. Spectrochim. Acta, Part A 2008, 69, 319-326.

(42) Truica-Marasescu, F.; Wertheimer, M. R. Nitrogen-Rich PlasmaPolymer Films for Biomedical Applications. Plasma Processes Polym. 2008, 5, 44-57.

(43) Compton, O. C.; Dikin, D. A.; Putz, K. W.; Brinson, L. C.; Nguyen, S. T. Electrically Conductive "Alkylated" Graphene Paper Via Chemical Reduction of Amine-Functionalized Graphene Oxide Paper. Adv. Mater. 2010, 22, 892-896.

(44) Huang, Y. L.; Tien, H. W.; Ma, C. C. M.; Yang, S. Y.; Wu, S. Y.; Liu, H. Y.; Mai, Y. W. Effect of Extended Polymer Chains on Properties of Transparent Graphene Nanosheets Conductive Film. J. Mater. Chem. 2011, 21, 18236-18241.

(45) Chen, Z. Q.; Dai, X. J. J.; Lamb, P. R.; Leal, D. R. D.; Fox, B. L.; Chen, Y.; du Plessis, J.; Field, M.; Wang, X. G. Practical Amine Functionalization of Multi-Walled Carbon Nanotubes for Effective Interfacial Bonding. Plasma Processes Polym. 2012, 9, 733-741.

(46) Shard, A. G.; Whittle, J. D.; Beck, A. J.; Brookes, P. N.; Bullett, N. A.; Talib, R. A.; Mistry, A.; Barton, D.; McArthur, S. L. A Nexafs Examination of Unsaturation in Plasma Polymers of Allylamine and Propylamine. J. Phys. Chem. B 2004, 108, 12472-12480.

(47) Briggs, D.; Brewis, D. M.; Dahm, R. H.; Fletcher, I. W. Analysis of the Surface Chemistry of Oxidized Polyethylene: Comparison of Xps and Tof-Sims. Surf. Interface Anal. 2003, 35, 156-167. 